neers and effecting technology transfer, vital for Africa's economic and industrial development.

To some extent, this is a "chicken-and-egg" situation, as industrial development can only take place when there is a pool of trained technical manpower, and the training of technical personnel is dependent of industry's absorptive capacity. A national assessment of both engineering capacity and needs in African countries can be of great help toward this end.

\section{Is There a Chinese Model of a University?}

\section{Qiang Zha, Jinghuan Shi, and Xiaoyang Wang}

Qiang Zha is an associate professor at the Faculty of Education, York University, Toronto, Canada. E-mail: qzha@edu.yorku.ca. Jinghuan Shi is a professor and executive dean of Institute of Education, Tsinghua University, Beijing, China. E-mail: shijhuan@mail.tsinghua.edu. cn. Xiaoyang Wang is an associate professor and director of Higher Education Research Institute, Tsinghua University, Beijing, China. Email:wangxy@tsinghua.edu.cn. This article is an abridged version of a chapter to be published in Handbook of the Sociology of Higher Education, Routledge.

T $\mathrm{n}$ the past decade and a half, Chinese higher education 1 struck the world with its amazing pace of expansion. The aggregate enrollment grew at an annual rate of I7 percent between 1998 and 2010. In the meantime, the Chinese government has been investing hugely in elite university schemes, in order to raise some universities and programs to a world-class level. This move has triggered a worldwide competition, in efforts to create world-class universities. China's current triumph in higher education expansion has aroused some discussions and debates, over whether or not there might be an emerging Chinese model of the university. This essay provides an overview of the inquiries into this theme.

\section{Two Major Approaches to Discerning the Chinese MODEL}

Two major approaches underlie the exploration of the Chinese model: the historical-cultural approach and the sociopolitical approach. The former embeds this discourse in the Confucian knowledge tradition. In the methodological sense, a knowledge tradition embodies the enduring modes of thinking or the salient features of cultural selfunderstanding, which would inevitably function to shape the particular contour of development in any given society. So, it is with the Confucian scholarly tradition with respect to Chinese universities. Though the university as an organizational form has been imported to Chinese soil only for a century or so; yet, as an organization of learning, it is naturally connected to the ethos of Confucian scholarship, which dominated Chinese education for over 2,000 years. Along the tradition line, the notion of liberal education now appears to be an optimal antidote to decadence in Chinese universities. Liberal education could be connected to the Confucian knowledge tradition that places emphasis on humanistic education, and thus implies learning from the past, rather than borrowing from the West. A Chinese name is often given to such practices, tong shi education, in order to differentiate it from the Western concept. Historically, China enjoyed profounder humanistic education, than Renaissance humanism in Europe. Hence, the past decade witnessed that Chinese universities had been increasingly encouraged to adopt the idea of liberal education and reorganize and broaden their curricula. Notably, many liberal education units in Chinese universities name themselves shuyuan (private academies of classical learning that flourished in the Tang and Song dynasties), in a deliberate effort at linking themselves to the Confucian tradition.

The historical-cultural approach draws heavily on the conception of the ideal type. The ideal type is often a useful tool to analyze historically unique configurations, by means of generic concepts. Nonetheless, it is argued that the current Chinese university may hardly be able to claim an ideal type formed from characteristics of and elements in the Confucian tradition-after a century of experimenting with various Western and Soviet patterns and absorbing their influences. The shupuan, even if recovered, has lost its cultural milieu in contemporary Chinese society. So, not surprisingly, research has indicated the impact of tong shi education in a current context as superficial, based on its utilitarian approaches associated with political agenda of creating "world-class" universities or marketing the goal of particular branding campaigns. As such, tong shi education has become more a matter of rhetoric than reality and failed to bring about significant transformation in the students' learning experiences.

The contemporary sociopolitical approach holds that the Chinese model for sociopolitical development (or the "Beijing Consensus"), which constitutes the normative environment in which Chinese universities operate, denotes a central role of the state and places emphasis on efficiency for the sake of accelerating economic growth. This model certainly finds its expression in Chinese universities. It carries advantages with respect to effective mobilization of resources and the capacity to expand and upgrade infrastructure dramatically in a short timeline. Consequently, the 
Chinese system stands out in the sense of simultaneously pushing for rapid enrollment growth, constituting new governance structures, and seeking to build world-class universities. These features concerning Chinese universities all mirror the strong state initiatives and momentum. During the peak years of expansion, China's fiscal appropriations for higher education increased annually at I7.4 percent between I998 and 2006. In 2012, China's top 50 researchintensive universities averaged their nominal research revenue at approximately US\$200 million, a figure far exceeding the singular highest in 2000-Tsinghua University's roughly US\$70 million that year. As a result, Chinese

\section{Two major approaches underlie the exploration of the Chinese model: the historical-cultural approach and the so- ciopolitical approach.}

universities now confer nearly a quarter $(24 \%)$ of world's science and engineering degrees, which are perceived to be of greatest importance to a knowledge-based economy. Between 200I and 20II, China's share of refereed science and engineering journal articles almost quadrupled, from 3 percent to II percent of the world total. This renders China now as the second-largest science and engineering article producer country (only behind the United States), and China's share of the top I percent articles enjoyed a six-fold increase over this period. These figures suggest China's great leap in higher education development, both in terms of quantity and quality, owes much to generous support from the state.

The contemporary sociopolitical approach adopts the open-system theory. The open-system theorists hold that higher education is a system essentially located within a suprasystem - consisting of the social, political, and economic environment. This system is open always with interaction of the environment-through which universities come to accept certain values and adapt to structures and processes judged to be important by the environment. However, the practice-based reasoning behind the "Beijing Consensus," which stresses and pursues tangible interests, has caused pragmatism and utilitarianism to prevail in Chinese society and academia. Furthermore, the integral gradualism (exemplified best in the phrase "crossing the river by groping for stepping stones") has arguably held back critical efforts at institutionalizing a regulatory environment. Consequently, there appears to be a paradox: on one hand, in recent years Chinese universities have been accorded an increas- ing degree of decision-making power over their own affairs (in exchange for their performance and accountability); on the other hand, the Chinese government may tighten its control over the universities, whenever it feels necessary.

Methodological LIMITATIONS OF THESE TWO APPROACHES Notwithstanding the merit of the historical-cultural approach, it has the flaw of lacking a sound contextualization of the discourse of the Chinese model with coherence and interconnections among traditional and contemporary elements, albeit that this approach should indeed be context bound. More precisely, it suffers from the discontinuity of the Chinese cultural tradition in the current "disrupted society." The current context for the Chinese university is much different from the traditional one, in which the historical culturalists stage this discourse, and a pure traditional context can hardly be restored. Such a fundamental change should affect the validity of the tradition determinism that underpins the historical-cultural discourse.

The contemporary sociopolitical approach enjoys the merit of situating the Chinese model discourse in current and real-life conditions, which in turn provides a useful means to include a wide array of social, political, and economic factors into the analysis. Put explicitly, it literally identifies the Chinese experience as unparalleled, peculiar only to the Chinese milieu, while not duplicable elsewhere. If that is the case, the Chinese experience can hardly claim the status of a Chinese model, as a model needs to provide for others inspirations and an impetus toward progress.

\section{CONCLUSION}

Both the approaches described above place the emphasis on a kind of Chinese exceptionalism, either reflecting the traditional cultural context or the current sociopolitical patterns. This in turn has caused a standstill in the scholarly inquiry into the phenomenon in question, resulting from such perceived dichotomies: the Confucian tradition vs. modern axiology, the Chinese characteristics vs. the world culture. We believe that to set the Confucian tradition, as opposed to contemporary values, may lose sight of the enduring modes of tradition and the salient features of cultural communications. As a matter of fact, contemporary Confucian discourse itself is now constituted globally as an integral part of the ideology of globalization. The close articulation, observed in China, between operation of the university and political agenda of the state can also be linked to one principal philosophy that legitimate the university in the West: the political philosophy of higher education, which justifies the university due to its far-reaching significance for the body politic. We thus suggest situating this discourse in a broader context of globalization, which opens the door for observing and investigating the (evolution of) 
interactions between the Chinese elements and those in the Western systems of higher education ever since the Igth century or an even earlier point. From there, we argue that a possible Chinese model of the university should arise from a creative and organic engrafting of elements in the Confucian tradition and the Western patterns, as well as in different cultures. Put in another way, the emerging Chinese model of the university is by no means peculiar to the Chinese context, but resembles certain characteristics of other systems or models. This approach might shed light on the notion that it is the combination of different characteristics (Confucian and Western) that makes the Chinese model unique. Nevertheless, it remains a question if the Chinese model is a variant of the global model of the university or an alternative.

\section{News of the Center}

Center director Philip G. Altbach spoke at two conferences in Tokyo, Japan, in February-one on liberal arts and the other concerned with internationalization. His visit was sponsored by Toyo University. He continues to serve on the Russian 5-100 Committee and will be participating in a session in Tomsk, Russia, in March. Philip G. Altbach, along with Kara Godwin, CIHE visiting scholar, will participate in a conference on liberal arts in Shanghai, China, in May. Altbach's edited book, Liderazgo para Universidades de Clase Mundial, has been published in Spanish by the Universidad de Palermo in Argentina.

Philip G. Altbach has been given the 2014 Lifetime Contribution Award in Comparative, International, and Development Education by the Institute of International Studies in Education at the University of Pittsburgh. Altbach is speaking at a workshop for all of the rectors of universities in Saudi Arabia, in April, and continues to serve on the planning committee of the International Conference on Higher Education for the Saudi Ministry of Higher Education. He will participate in an international conference on the liberal arts in Shanghai, China, sponsored by the Harvard China Fund and the Amsterdam University College.

Academic Inbreeding and Mobility in Higher Education: Global Perspectives, coedited by Maria Yudkevich, Philip G. Altbach, and Laura E. Rumbley, has been published by Palgrave Macmillan. Even more recently, Young Faculty in the 21st Century: International Perspectives, coedited by Maria Yudkevich, Philip G. Altbach, and Laura E. Rumbley, has been published by the State University of New York Press. These books are the product of the Center's continuing collaboration with the Laboratory for Institutional Analysis at the Higher School of Economics in Moscow. This collaboration is also enabling the elaboration of another project currently underway, which focuses on rankings and their impact on specific universities in II countries. This project will result in a book, as well.

In April 20I5, the Center will copublish, with the American Council on Education's Center for Internationalization and Global Engagement, a new number in the "International Briefs for Higher Education Leaders" series. Number 5 in this series will focus on the subject of international joint- and dual-degree programs. An American Council on Education-sponsored webinar, also in April, will complement this publication.

The Center is pleased to announce that its extensive 20I4 publication, Higher Education: A Worldwide Inventory of Research Centers, Academic Programs, and Journals (3rd edition), will be freely available for download from the CIHE Web site, as of April 20I5. The Center is currently conducting a small follow-up survey from that inventory work, this time focusing explicitly on the profiles and activities of those research centers around the world that are in some way undertaking research specifically in the field of "international higher education." This work is being undertaken by Center associate director Laura E. Rumbley and doctoral research assistants Ariane de Gayardon and Georgiana Mihut.

In early March, Laura E. Rumbley delivered a keynote address at the Norwegian Conference on Internationalisation 2015, organized by the Norwegian Centre for International Cooperation in Education (SIU) and held in Tromsø, Norway.

Philip G. Altbach and Laura E. Rumbley will both be participating in several NAFSA: Association of International Educators annual conference sessions in Boston in May. The Center will also host an invitation-only event at Boston College on May 28, 20I5, to mark the 2oth anniversary of the Center's establishment.

We warmly welcome newly arrived visiting scholars Julie Mathews-Aydinli (Bilkent University, Turkey) and Zhao Liu (Peking University, China). 